\title{
Clinical Evaluation of Growth Hormone Secretion in Cattle Using Insulin Tolerance Test
}

\author{
Masafumi OGURO ${ }^{1)}$, Hirotaka ISHIKAWA ${ }^{1)}$, Hiromichi OHTSUKA ${ }^{1)}$, Fumio HOSHI ${ }^{1)}$ and Seiichi KAWAMURA ${ }^{1)}$ \\ ${ }^{1)}$ Department of Veterinary Internal Medicine, School of Veterinary Medicine and Animal Science, Kitasato University, Towada, Aomori \\ 034-8628, Japan
}

(Received 28 October 2002/Accepted 17 March 2003)

ABSTRACT. Growth hormone secretion was evaluated in cattle. Clinically healthy bovine growth hormone (bGH) concentrations were 10.7 $\pm 1.6 \mathrm{ng} / \mathrm{ml}$ in Holstein and $7.8 \pm 3.9 \mathrm{ng} / \mathrm{ml}$ in Japanese black cattle. The bGH concentration alternated at three-hour intervals, and tended to be higher at midnight and lower in the morning and before feeding. Insulin tolerance test (ITT) at an insulin dosage of 0.25 $\mathrm{U} / \mathrm{kg}$ showed a significant increase of bGH concentration to $331 \pm 153 \%$ at 60 to 90 min after injection. In ITT applied to five undergrowth calves of Japanese black cattle, the basal bGH concentrations were lower and peak values after insulin injection were shown to be significantly low. The ITT is useful for the clinical examination of bGH secretion in cattle.

KEY WORDS: bovine growth hormone, cattle, insulin tolerance test.

J. Vet. Med. Sci. 65(7): 809-812, 2003

Disorders of growth hormone $(\mathrm{GH})$ secretion are known to produce dwarfism and acromegaly in humans $[5,8]$. There are few reports on such disorders in animals, however, in recent years, the number of calves showing congenital weakness or poor growth has been increasing $[4,9,10$, 17]. Clinico-pathological and genetic research has been done on these disorders $[9,10]$, but the etiology of these disorders remains to be elucidated because the methods of endocrinological examination in cattle have yet to be established. The insulin tolerance test, L-Dopa test and GHreleasing hormone $(\mathrm{GHRH})$ test are common endocrinological examinations for evaluating pituitary $\mathrm{GH}$ secretion in human medicine $[5,8]$. However, such investigations in cattle have been rarely reported. The objective of the present study was to establish a method of evaluating bovine growth hormone (bGH) secretion in order to elucidate the functional properties of the anterior pituitary in cattle.

Blood sampling and serum separation were carried out by routine clinical methods. The sera were stored at $-80^{\circ} \mathrm{C}$ until used.

The bGH concentrations in serum were determined by the sandwich enzyme immunosorbent assay (ELISA) commonly referred to as Secchi's method [14]. The bGH standard and its antiserum were provided by Dr. A.F. Parlow of the National Hormone and Peptide Program (Harbar-UCLA Medical Center, U.S.A.). The blood glucose concentrations were determined with the Glucose-C Test Wako (Wako, Tokyo).

All values were expressed as mean $\pm \mathrm{SD}$. Student's $t$-test was used for statistical analysis of the data.

Basal concentrations of bGH in the serum of healthy cattle were determined. In this study, twenty-four adult cattle [twelve Holstein (667 $\pm 27 \mathrm{~kg}$ b.w.) and twelve Japanese Black (beef cattle, $662 \pm 52 \mathrm{~kg}$ b.w.)] were used. These cattle were fed a diet formulated to meet nutrient requirements as recommended by the Japanese Feeding Standard (1998).
All blood samplings were carried out at 8:00 AM before the morning feeding. The mean concentrations of bGH were found to be $10.7 \pm 1.6 \mathrm{ng} / \mathrm{ml}$ in Holsteins, and $7.8 \pm 3.9 \mathrm{ng} /$ $\mathrm{m} l$ in the Japanese Black. The difference between these values was statistically significant $(\mathrm{p}<0.05)$.

The determination of the bGH secretion pattern, that is, its circadian variation over $24 \mathrm{hr}$ (from 4:00 AM to 4:00 AM of the following day) was examined in four Holsteins which were housed indoors and fed twice a day (8:00 AM and 4:00 PM). Blood samples were collected from the jugular vein at 60-min intervals. The bGH secretion patterns are shown in Fig. 1. Pulsate changes of bGH concentrations were observed at 3 to $4 \mathrm{hr}$ intervals. The bGH concentration tended to be relatively high around midnight, but was low early in the morning and after the feeding.

Four Holstein cows were used for the Insulin tolerance test (ITT) in order to examine the secretory response of bGH to insulin injection. Recombinant human insulin (Novolin R 40, Novo Nordisk, Denmark) at doses of 0.20, 0.25 and $0.30 \mathrm{U} / \mathrm{kg}$ (body weight) was injected intravenously. Blood was sampled through the jugular vein on the other side of the neck at $0,15,30,45,60,75,90,105,120,150$ and 180 min after injection. As a control, $0.9 \%$ sodium chloride solution was injected to the same cattle used under the same conditions. The changes in serum bGH concentration after each injection of insulin are shown in Fig. 2, and the changes of blood glucose level are shown in Fig. 3. The bGH concentrations increased slightly after the injection of insulin at $0.20 \mathrm{U} / \mathrm{Kg}$, although the changes were not significant. However, the increases of $\mathrm{GH}$ after the injection of insulin at dosages $>=0.25 \mathrm{U} / \mathrm{Kg}$ were significant. The $\mathrm{bGH}$ concentration reached a peak value $(35.0 \pm 11.0 \mathrm{ng} / \mathrm{ml}) 75$ min after injection of $0.25 \mathrm{U} / \mathrm{Kg}$ insulin. The percentage of peak values to basal values (PPB) was $331 \pm 153 \%$. The bGH peak $(39.0 \pm 5.8 \mathrm{ng} / \mathrm{m} l)$ was also found $75 \mathrm{~min}$ after injection of $0.30 \mathrm{U} / \mathrm{Kg}$ insulin, while the RPB was $401 \pm$ 

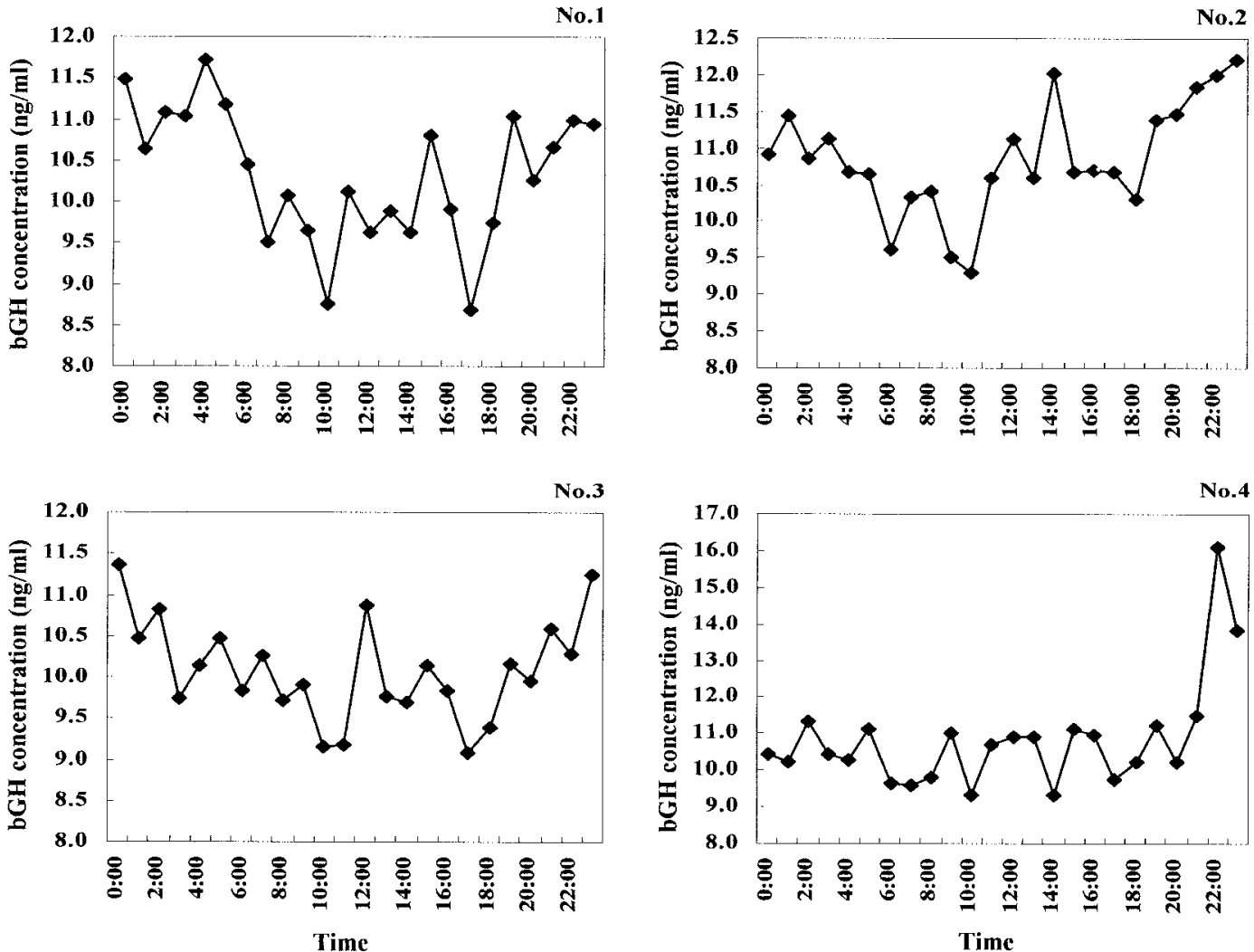

Fig. 1. Daily variation of serum bGH concentration. The cattle were housed indoors and fed twice daily at 8:00 AM and 4:00 PM.

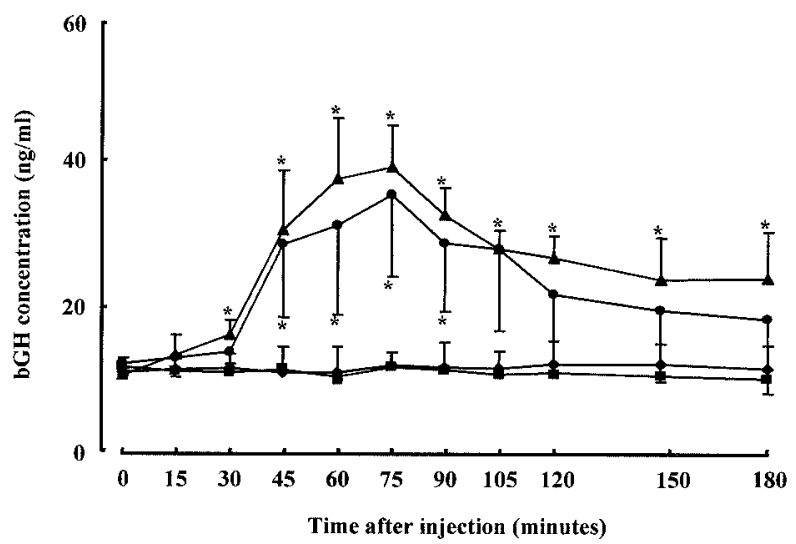

Fig. 2. Change of bGH concentrations in the Insulin tolerance test. Dose of insulin injection; $\mathbf{a}$ : Control (0.9\% sodium chloride), $0.20 \mathrm{U} / \mathrm{kg}, 0.25 \mathrm{U} / \mathrm{kg}, \boldsymbol{\Delta}: 0.30 \mathrm{U} / \mathrm{kg}$. Asterisks show significant differences from the value before insulin injection (at $0 \mathrm{~min})($ mean $\pm 1 \mathrm{SD})$.

$43 \%$. Symptoms such as trembling, convulsions and recumbency appeared due to hypoglycemia in two of the cattle after injection at this dosage. In those cases, the glucose level declined to less than $20 \mathrm{mg} / \mathrm{d} l$.

Next, ITT was applied to five normally developed Japanese Black calves (NDJB) and five underdeveloped Japa-

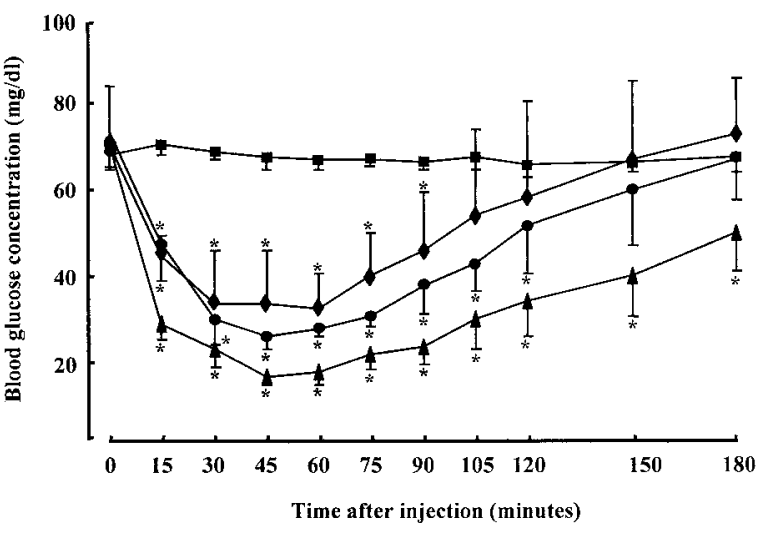

Fig. 3. Change of blood glucose concentrations in the Insulin tolerance test. Dose of insulin injection; $\mathbf{\square}$ : Control $(0.9 \%$ sodium chloride), $: 0.20 \mathrm{U} / \mathrm{kg}, \boldsymbol{0}: 0.25 \mathrm{U} / \mathrm{kg}, \boldsymbol{\Delta}: 0.30 \mathrm{U} / \mathrm{kg}$. Asterisks show significant differences from the value before insulin injection (at $0 \mathrm{~min})($ mean $\pm 1 \mathrm{SD})$.

nese Black calves (UDJB) (Table 1). All the UDJB calves were under-grown as a result of repeated pneumonia and diarrhea. These UDJB were fed roughage and concentrates at random. On the other hand, all NDJB were recognized to be healthy and fully developed. The changes in serum GH concentration in ITT are shown in Fig. 4. Basal bGH con- 
Table 1. Calves used for Insulin tolerance test

\begin{tabular}{|c|c|c|c|c|c|}
\hline & $\begin{array}{c}\text { Age } \\
\text { (months) }\end{array}$ & Sex & $\begin{array}{l}\text { Body weight } \\
(\mathrm{kg})\end{array}$ & $\begin{array}{c}\text { Standard body } \\
\text { weight }^{\text {al }}(\mathrm{kg})\end{array}$ & $\begin{array}{c}\mathrm{BWI}^{\mathrm{b})} \\
(\%)\end{array}$ \\
\hline$U^{(D J B}{ }^{c} 1$ & 12.0 & 우 & 106 & 291 & 36 \\
\hline UDJB2 & 18.3 & $\hat{0}$ & 108 & 374 & 29 \\
\hline UDJB3 & 1.2 & 우 & 30 & 55 & 55 \\
\hline UDJB4 & 5.6 & 우 & 30 & 155 & 19 \\
\hline UDJB5 & 5.1 & $\hat{\delta}$ & 88 & 143 & 62 \\
\hline $\mathrm{NDJB}^{\mathrm{d})} 1$ & 7.6 & 우 & 190 & 200 & 95 \\
\hline NDJB2 & 6.3 & $\hat{0}$ & 187 & 170 & 110 \\
\hline NDJB3 & 7.2 & 우 & 174 & 191 & 91 \\
\hline NDJB4 & 6.6 & $\hat{\delta}$ & 195 & 177 & 110 \\
\hline NDJB5 & 7.5 & & 192 & 198 & 97 \\
\hline
\end{tabular}

a) Standard body weight is shown as the weight set at each age in the Japanese Feeding Standard [1].

b) Body Weight Index: Percentage of the standard body weight of Japanese Black calf at same age [1].

c) Underdeveloped Japanese Black calves.

d) Normally developed Japanese Black calves.

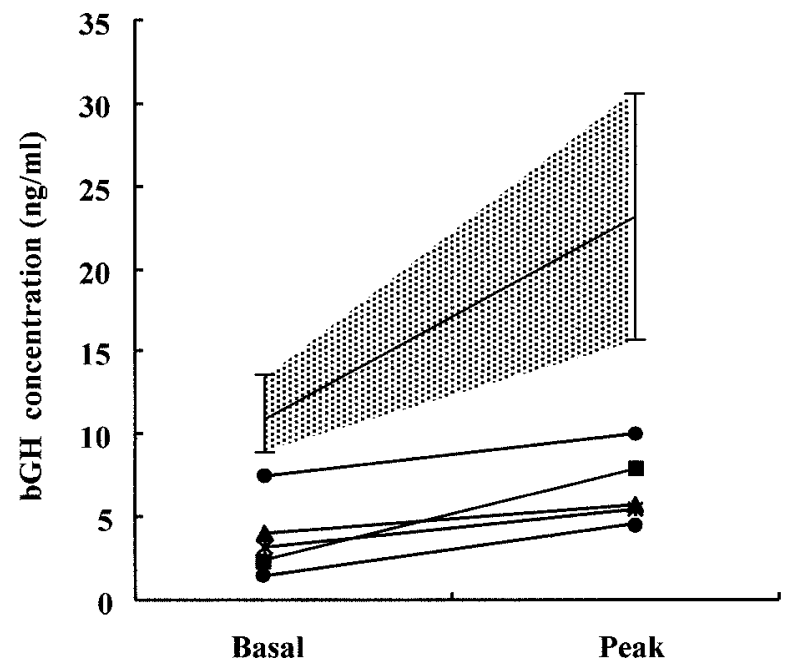

Fig. 4. Insulin tolerance test in underdeveloped cattle. Basal means of basic bGH concentration before insulin injection and means of peak bGH concentration after insulin injection. Mesh area expresses bGH secretion in healthy cattle grown normally (Japanese Black) (mean \pm 1 SD).

centrations in the serum of NDJB were $10.5 \pm 2.6 \mathrm{ng} / \mathrm{ml}$, and peak values in ITT were $22.3 \pm 7.1 \mathrm{ng} / \mathrm{ml}$. This difference was significant $(\mathrm{p}<0.05)$ and the PPB was $221 \pm 82 \%$. On the other hand, in UDJB, the basal level was $3.5 \pm 2.0 \mathrm{ng} / \mathrm{ml}$, and the peak value of $6.6 \pm 2.0 \mathrm{ng} / \mathrm{m} l$ was attained during a wide time period from $45-90 \mathrm{~min}$ after the injection. PPB was $233 \pm 94 \%$. Basal and peak values in UDJB were significantly different compared with those in NDJB $(\mathrm{P}<0.05)$.

The bGH concentrations in the sera of normal cattle in this study resembled the values reported in Holstein cows by Koprowski [11]. However, there are few reports about serum bGH values in beef cattle, especially in Japanese
Black. It is expected that bGH determination will be useful as a predictive index of milk and beef productivity in cattle, because it is connected not only with their development but also with the metabolism of proteins and lipids [2, 6].

The circadian changes of bGH concentration showed various patterns according to Koprowski et al. [11], and Wheaton and Tucker et al. [15]. Our result showing that bGH concentration tended to be higher in midnight and lower in the early morning and after feeding was very similar to those found in other mammals $[5,12,18]$. The present result indicated that blood sampling for the evaluation of basal bGH concentration should be carried out in the early morning because it showed the most stable value, and also that it is difficult to evaluate bGH secretory activity in the pituitary gland with only one-point sampling.

It is known that a decline in blood glucose level induced by insulin injection induces massive GHRH secretion from the hypothalamus $[3,5,7]$. Based on these reports, ITT has been applied to the assessment of secretory function in the anterior lobe of the pituitary gland in human medicine [8]. However, in ruminants there are very few reports about ITT in endocrinological and metabolic research $[12,13]$. Therefore data on safe and effective doses of insulin injection and normal patterns of bGH secretion are needed before ITT can be introduced to cattle as a clinical examination.

The blood glucose levels after $0.20 \mathrm{U} / \mathrm{kg}$ insulin injections decreased significantly, but the increases of bGH levels were not significant. It is possible that other hormones such as glucagons or glucocorticoid might have compensated for the decrease in blood glucose, and that this blood glucose level might be insufficient to induce significant bGH secretion from the pituitary gland $[3,5,7]$. At $0.25 \mathrm{U} /$ $\mathrm{kg}$ of insulin, significant decreases of blood glucose and increases of bGH level were observed. The blood glucose level in these animals decreased to less than $30 \mathrm{mg} / \mathrm{d} l$ at 30 min after injection but no nervous symptoms were observed. 
This result suggests that a remarkable decline of blood glucose level is needed for effective stimulation of bGH secretion. At $0.30 \mathrm{U} / \mathrm{Kg}$ of insulin injection, glucose levels decreased dramatically and some nervous symptoms were induced due to hypoglycemia, indicating that $0.30 \mathrm{U} / \mathrm{kg}$ represented an overdose level.

There is a report of ateliosis caused by hereditary hypopituitarism in a calf [16]. However, there have been no reports on the secretory function of bGH in underdeveloped cattle that have suffered from continued and repeated diarrhea and pneumonia. Body weights and body lengths of the UDJB in this study were less than half the standards for Japanese Blacks [1]. It is likely that the secretory function of the pituitary gland in UDJB had been extremely suppressed because basal bGH levels, peak values and RPB were remarkably low. These results in UDJBC are comparable with those in hypophysical growth hormone deficiency in human medicine $[5,8]$. However, more versatile and endocrinological investigations will be necessary in order to clarify the etiology.

So far no information has been available on proper doses for ITT in cattle. Based on our present results, we suggest that the following standards are adopted for the use of ITT in cattle: the insulin dose should be $0.25 \mathrm{U} / \mathrm{kg}$ body weight, which should be injected intravenously, and blood sampling should be done at $0,45,60,75$ and 90 min after the injection. GH secretory function should be evaluated by determining basal values, and then peak values after insulin injection. In conclusion, it is anticipated that ITT will be useful not only for the diagnosis of endocrine diseases but also for the differential diagnosis of metabolic diseases.

\section{REFERENCES}

1. Agriculture, Forestry and Fisheries Research Council Secretar- iat Ministry of Agriculture, Forestry and Fisheries. 1998. Japanese Feeding Standard for Beef Cattle, Central Association of Livestock Industry, Tokyo.

2. Bines, J. A. and Hart, I. C. 1982. J. Dairy Sci. 65: 1375-1389.

3. Blackard, W. G. and Heideingsfelder, S. A. 1968. J. Clin. Invest. 68: 1407-1414

4. Furuhashi, T. and Sasaki, Y. 2000. J. Jpn. Vet. Med. Assoc. 53: 735-739.

5. Gittoes, N. J., Sarne, D. H., Frankly, J. A., Sheppard. M. C. and Samuel, R. 2001. Endocrinology, B. W. Saunders, Philadelphia.

6. Hart, I. C., Bines, J. A. and Morant, I. C. 1979. J. Dairy Sci. 62: 270-277.

7. Hertelendy, F. and Kipnis, D. M. 1973. Endocrinology 92: 402-410.

8. Howanitz, j. H. and Howanitz, P. J. 1995. Laboratory Medicine, Churchill Livingstone, New York.

9. Ishibashi, M., Ushinohama, K., Kamimura, S. and Hamana, K. 1999. J. Jpn. Vet. Med. Assoc. 52: 427-430.

10. Kitagawa, H., Kito, K., Ito, T., Oba, Y., Kanazawa, K., Hasegawa, H., Kawai, Y., Kobayashi, M., Inaba, M. and Miyake, Y. 2000. J. Vet. Clin. 47: 83-91.

11. Koprowski, J. A., Tucker, H. A., and Convey, E. A. 1972. Proc. Soc. Exp. Bio. Med. 140: 1012-1014.

12. McAtee, J. W., and Trenkle, Allen. 1971. J. Anim. Sci. 33: 612-616.

13. Reynaert, R., Paepe, M., Marcus, S. and Peeters, G. 1975. J. Endocrinol. 66: 213-224.

14. Secchi, C., Biondi, P. A., Berrini, A., Simonic, T. and Ronchi, S. 1988. J. Immunol. Methods 110: 123-128.

15. Tucker, H. A., Koprowski. J. A., Britt, J. H. and Oxender, W. D. 1973. J. Dairy Sci. 57: 1092-1094.

16. Yaguchi, N., Yamashina, J., Ban, K. and Hoshi, M. 1995. J. Vet. Clin. 382: 15-21.

17. Yoneshige, R., Furukawa, M., Nojiri, Y., Ozaki, H., Uemura, S. and Hamana, K. 1998. J. Vet. Clin. 419: 289-295.

18. Wheaton, J. E., Al-Raheem, S. N., Massri, Y. G. and Marcek, J. M. 1986. J. Anim. Sci. 62: 1267-1272. 